\title{
Early and Late Effects of Hyperbaric Oxygen Treatment on Oxidative Stress Parameters in Diabetic Patients
}

\author{
F. GÜRDÖL ${ }^{1}$, M. CIMŞIT ${ }^{2}$, Y. ÖNER-IYYIDOĞAN ${ }^{3}$, Ş. KÖRPINAR ${ }^{2}$, S. YALÇINKAYA $^{1}$, \\ H. KOÇAK ${ }^{1}$
}

${ }^{1}$ Department of Biochemistry and ${ }^{2}$ Department of Underwater and Hyperbaric Medicine, Istanbul Faculty of Medicine, Istanbul University, Çapa, Istanbul, ${ }^{3}$ Medical Services Training School, Medical Laboratory Program, Istanbul University, Cerrahpaşa, Istanbul, Turkey

Received October 17, 2006

Accepted November 24, 2006

On-line available January 2, 2007

\section{Summary}

Exposure to hyperbaric oxygen leads to increased amount of reactive oxygen species (ROS) that are derived from various sources. After the discovery that ROS can function as signaling molecules, the idea of ROS being hazardous to biological tissues has been challenged. The aim of this study was to examine the changes in oxidative stress parameters in diabetics undergoing hyperbaric oxygen therapy (HBOT) due to foot ulcers. Twenty patients, who received HBOT for diabetic foot ulcers, were included in the study. Blood samples were taken before HBOT and $30 \mathrm{~min}$ after exit from the chamber, on the day of the first and the 15th HBOT sessions. They were used for the determinations of malondialdehyde (MDA), 8-isoprostane and advanced oxidation protein products (AOPPs). 8-Isoprostane and AOPP levels were not altered significantly after the first HBOT session, while both were increased on the fifteenth day $(p<0.05)$. MDA was significantly increased only after the first HBOT session, and remained unchanged on the fifteenth day (within-day variations). Plasma AOPP levels were lowered significantly after fifteen consecutive HBOT sessions (between-day variations). Decreased AOPP levels suggest that increased oxygenation of tissues due to HBO therapy may activate some endogenous factors that prevent hazardous effects of the disease itself.

\section{Key words}

Isoprostanes • Hyperbaric oxygen • Malondialdehyde • Advanced oxidation protein products $\bullet$ Diabetic foot

\section{Corresponding author}

Figen Gürdöl, Department of Biochemistry, Istanbul Faculty of Medicine, Çapa, 34093, Istanbul, Turkey.

E-mail: figur@istanbul.edu.tr

\section{Introduction}

Hyperbaric oxygen (HBO) therapy has been successfully used for the treatment of a variety of clinical conditions related to hypoxia, including acute carbon monoxide intoxication, air embolism, soft tissue infections, radiation necrosis and impaired wound healing (Wattel 1998, Feldmeier 2003). Exposure to HBO leads to an increase in the amount of dissolved oxygen and reactive oxygen species (ROS) in the blood. An excessive generation of highly reactive oxidants results in tissue damage, called as oxidative stress. ROS are derived from a variety of sources, such as the xanthine oxidase system, activated neutrophils, the electron transport chain of mitochondria, and the arachidonic acid pathway. Since free radicals have very short half-lives, the clinical assessment of oxidative stress in vivo is based on the measurement of different stable oxidized products of modified lipids, proteins, carbohydrates and nucleic acids. Malonyldialdehyde (MDA), one of the mostwidely used biomarkers of oxidative stress, is produced enzymatically by the breakdown of unstable hydroperoxides during peroxidation of unsaturated fatty acyl moieties. 8-Isoprostane (8-isoPGF $2 \alpha)$, an isomer of $\mathrm{F}_{2}$-isoprostanes, is produced nonezymatically from arachidonic acid, and used as a stable index of freeradical attack on membrane phospholipids (Roberts and Morrow 2000). Proteins are also susceptible to oxidantmediated injury, forming cross-linkage and aggregation products that are resistant to proteolysis. Markers of protein oxidation were characterized by Witko-Sarsat et 
al. (1996), and named as advanced oxidation protein products (AOPPs), since they share several homologies with advanced glycosylation end-products (AGEs), which also indicate oxidant-mediated damage.

The oxidative effects of $\mathrm{HBO}$ have been investigated in animals and humans (Jamieson 1991, Oter et al. 2005, Dennog et al. 1999, Eken et al. 2005). Dennog et al. (1999) have determined the antioxidant response to a single $\mathrm{HBO}$ exposure in healthy humans, finding no significant differences in antioxidant levels and antioxidant enzymes involved in the primary defense against oxidative damage before and $24 \mathrm{~h}$ after the HBO session. However, the conditions of HBO therapy are not applicable to above-mentioned study, because the patient is repeatedly exposed to hyperbaric oxygen depending on the underlying disease. Recently, Eken et al. (2005) studied the effects of HBO therapy on oxidative stress in fifteen patients with various pathologies and reported that HBO did not cause any significant changes on erythrocyte antioxidant capacity and lipid peroxidation.

There is increasing evidence about the ability of $\mathrm{HBO}$ to induce cellular protection in a similar manner with other protective oxidative stress mechanisms, as reviewed recently (Yogaratnam et al. 2006). Repeated HBO exposure significantly attenuated the inflammatory mediators, free radicals, and mortality in endotoxic rats (Lin et al. 2005). Preconditioning by HBO treatment protected liver against subsequent ischemia-reperfusion injury in rats ( $\mathrm{Yu}$ et al. 2005), and induced tolerance against spinal cord ischemia in rabbits (Nie et al. 2006). These protective effects of HBO may be related to the fact that reactive oxygen species can trigger a wide variety of cellular mechanisms by functioning as signal molecules (Herrlich and Bohmer 2000, Rosette and Karin 1996, Dalton et al. 1999)

Diabetic patients have significant defects of antioxidant defense elements, and the generation of reactive oxygen species is one of the major determinants of diabetic complications (Opara 2002, Martin-Gallan et al. 2003, Abou-Seif and Youssef 2004, Gil-del Valle et al. 2005, Davi et al 2005). Diabetic patients with unhealing foot ulcers usually undergo HBO treatment. However, to our knowledge, there is no study with regard to the effects of $\mathrm{HBO}$ therapy on oxidative stress parameters in diabetics who are already characterized by increased production of reactive oxygen species.

The aim of this study was to examine the early and prolonged effects of hyperbaric oxygen on the levels of MDA, 8-isoPGF ${ }_{2 \alpha}$ (8-isoprostane) and AOPPs in non- insulin dependent diabetic patients who were exposed to hyperbaric oxygen for the treatment of foot ulcers.

\section{Methods}

Subjects

Twenty type 2 diabetic (T2DM) patients with foot ulcers who received hyperbaric oxygen therapy were included in the study. Local ethics committee approved the study protocol and all study subjects gave their informed consents. Patients were followed by the same physician responsible for diabetes control, wound care and antibiotic therapy according to the clinical and laboratory findings, and were given a diet depending on their metabolic needs without vitamin supplementation. Six patients were on statins owing to high levels of plasma lipids. Glucose levels were measured on the days when the parameters of oxidative stress were measured. No significant difference occurred in the glucose levels of patients during the experimental period. The characteristics of patients are shown in Table 1.

Table 1. Characteristics of the patients - fasting blood glucose and $\mathrm{HbA} 1 \mathrm{c}$ levels on the day of admission.

\begin{tabular}{ll} 
Number of patients & $\mathbf{2 0}$ \\
\hline Age (years) $*$ & $55(41-70)$ \\
Men/Women & $14 / 6$ \\
Intake of alcohol (yes/no) & $6 / 14$ \\
Smokers/non-smokers & $13 / 7$ \\
BMI $\left(\mathrm{kg} / \mathrm{m}^{2}\right) *$ & $25.3(19.4-29.7)$ \\
Duration of diagnosed DM (years) & $8.5(1-25)$ \\
Fasting blood glucose $(\mathrm{mg} / \mathrm{dl}) * *^{*}$ & $223 \pm 77$ \\
HbA $_{1 c}(\%) * *$ & $8.8 \pm 1.3$
\end{tabular}

$*$ median (range); ${ }^{* *}$ mean \pm S.D. HBO treatment

All subjects underwent HBO therapy according to a routine therapy protocol for diabetic foot ulcers with healing problems, determined by the European Committee on Hyperbaric Medicine and also by the Hyperbaric Oxygen Committee of Undersea and Hyperbaric Medicine (Wattel 1998, Feldmeier 2003). HBOT was carried out in a multiplace hyperbaric chamber once a day, and six days in a week. The treatment protocol was inhalation of $3 \times 25$ min periods of $100 \%$ oxygen at a pressure of 2.4 ATA, interspersed with 5 min periods of air breathing. 


\section{Sample collection}

Venous blood samples $(10 \mathrm{ml})$ were collected from each patient in standard sterile vacuum tubes containing EDTA. Samples were taken before HBO therapy and $30 \mathrm{~min}$ after the exit from the chamber, on the day of the first and 15th HBO sessions. Blood samples were immediately centrifuged at $600 \mathrm{~g}$ for $15 \mathrm{~min}$. Aliquots of plasma were stored at $-80^{\circ} \mathrm{C}$ for MDA and AOPP determinations. For the 8-isoprostane measurement, samples were kept at $-80^{\circ} \mathrm{C}$ in the presence of $0.005 \%$ BHT (butylated hydroxytoluene) to prevent oxidative formation of 8-isoprostanes.

\section{Analytical procedures}

8-Isoprostane: The concentration of total (free and phospholipid-bound) $\mathrm{F}_{2}$-isoprostane (8-isoPGF $\mathrm{F}_{2 \alpha}$ ) was analyzed using commercially available enzyme immunoassay kit (Cayman Chemicals, Ann Arbor, MI). Prior to analysis, plasma samples were hydrolyzed for separating the esterified 8-isoprostane in lipoproteins and purified for elimination of the contaminants. Purification of samples was made using affinity column (Cayman Chemicals, cat No: 416358). Each column was not used more than one regeneration cycle. The assay depends upon the competitive binding between the 8-isoprostane and an 8-isoprostane-acetylcholinesterase (AChE) conjugate (8-isoprostane tracer) for a limited number of 8 -isoprostane-specific rabbit antiserum binding sites. The concentration of 8-isoprostane was determined by interpolation from a standard curve. The detection limit was $5 \mathrm{pg} / \mathrm{ml}$. Plasma samples were not diluted and all values were within the detection limits $(5-500 \mathrm{pg} / \mathrm{ml})$. Microtiter assay plates were scanned with a computercontrolled adjustable wavelength microtiter plate reader (ELx800 Instruments). Results were expressed as pg/ml.

Malondialdehyde (MDA): This was determined in plasma by the 2-thiobarbituric acid reactive substances (TBARS) method (Buege and Aust 1978). 1,1,3,3 Tetraethoxypropane (Sigma, UK) was used as a standard. Results were expressed as $\mu \mathrm{mol} / 1$.

Advanced oxidation protein products (AOPPS): AOPPs were determined in plasma using the method devised by Witko-Sarsat et al (1996). AOPP concentrations were expressed as $\mu \mathrm{mol} / 1$ of chloramine- $\mathrm{T}$ equivalents.

\section{Statistics}

Results were expressed as means \pm S.D., and analyzed using repeated measures for two-way ANOVA

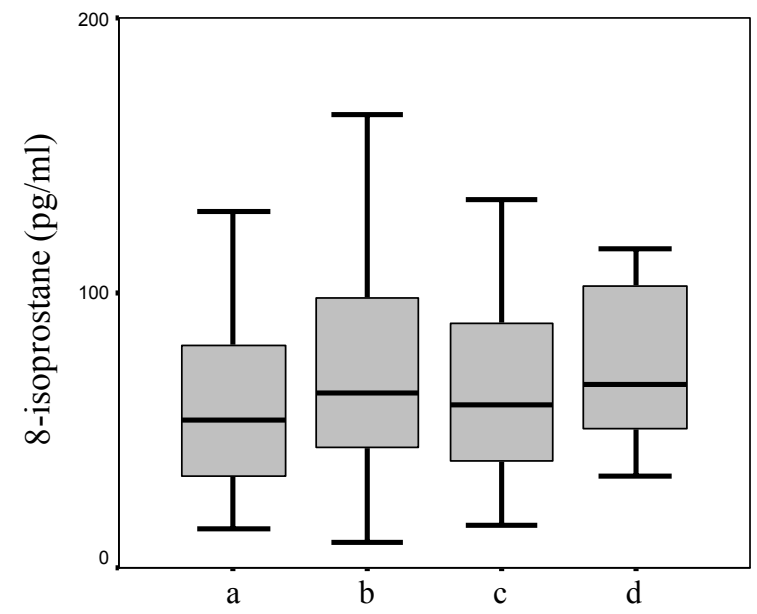

Fig. 1. 8-Isoprostane levels in 20 diabetic patients. Horizontal lines in boxes represent the median values, the boxes express $50 \%$ distribution, the upper lines express $75 \%$, and the lower $25 \%$ distributions. (a) $1^{\text {st }}$ day before HBOT, (b) $1^{\text {st }}$ day after HBOT, (c) $15^{\text {th }}$ day before HBOT, (d) $15^{\text {th }}$ day after HBOT. c versus d: $\mathrm{p}<0.05$.

after the logarithmic transformation of data for AOPP and isoprostanes. $\mathrm{P}<0.05$ values were regarded as significant. Pearson correlation analysis was performed to see any relation between oxidative markers. All analyses were performed with the SPSS statistical program (10.0 software version, SPSS Inc, Chicago, IL, USA).

\section{Results}

The levels of 8-isoprostane, AOPPs and MDA in patients before and after $\mathrm{HBO}$ exposure on the days of first and fifteenth therapy are shown in Figures 1-3, respectively.

Within-day variations: After the first $\mathrm{HBO}$ therapy, 8-isoPGF $2 \alpha$ and AOPP levels did not differ significantly when compared to the baseline values in diabetic patients. The baseline values were $67.8 \pm 42.8$ $\mathrm{pg} / \mathrm{ml}$ for 8 -isoPGF $2 \alpha$ and $289 \pm 206 \mu \mathrm{mol} / 1$ for AOPPs.

On the day of 15th session, 8-isoprostane levels were increased in $69 \%$ and AOPP levels were increased in $75 \%$ of the patients after HBO therapy. On the fifteenth day, mean levels of 8 -isoprostane were $68.9 \pm 38.3 \mathrm{pg} / \mathrm{ml}$ before the HBO treatment, and $96.4 \pm 78.7 \mathrm{pg} / \mathrm{ml}$ after the HBO therapy ( $<<0.05$; Fig. 1). Similarly, AOPPs exhibited a slight increase after HBO therapy on the fifteenth day $(176 \pm 122$ vs. $256 \pm 185$ $\mu \mathrm{mol} / \mathrm{l}, \mathrm{p}<0.05$; Fig. 3).

MDA concentration was significantly increased after the first HBO therapy with an increase in $75 \%$ of the patients ( $3.56 \pm 0.79$ vs. $3.951 .22 \mu \mathrm{mol} / 1, \mathrm{p}<0.05)$; but 


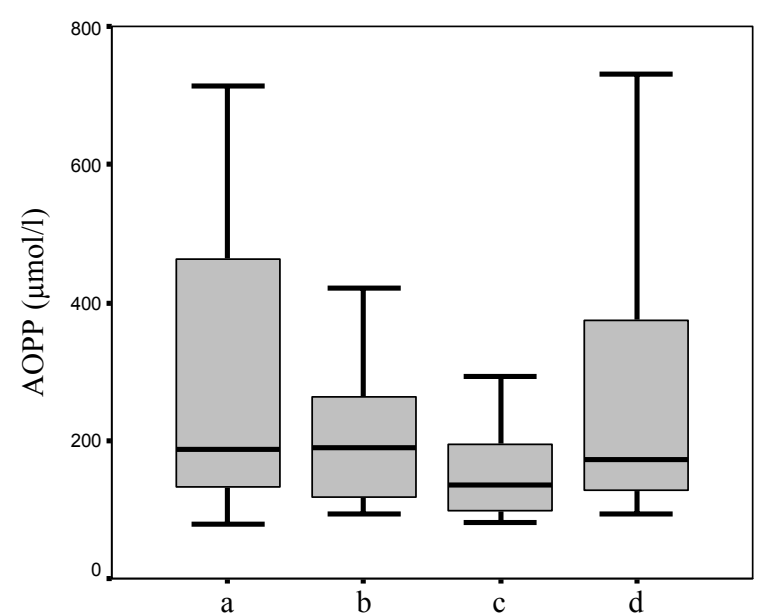

Fig. 2. Distribution of AOPP levels in patients $(n=20)$ before and after HBO therapy. Characteristics of the diagram are similar to Figures 1 and 3. (a) $1^{\text {st }}$ day before HBOT, (b) $1^{\text {st }}$ day after HBOT, (c) $15^{\text {th }}$ day before HBOT, (d) $15^{\text {th }}$ day after HBOT. c versus $\mathbf{a}$ and $\mathbf{d}: \mathrm{p}<0.05$.

it showed no within-day variation on the day of 15 th HBO treatment (Fig. 3).

Inter-day variations: Following fourteen consecutive HBO therapies, plasma AOPP levels were significantly lower prior to the fifteenth session in comparison to the basal level on the first day $(176 \pm 122$ $\mu \mathrm{mol} / 1$ vs. $289 \pm 206 \mu \mathrm{mol} / \mathrm{l}, \mathrm{p}<0.05$, Fig. 2). This decrement was observed in $75 \%$ of the patients, whereas MDA and 8-isoprostane levels did not exhibit any between-day variations.

There were no significant correlations among the three parameters of oxidative stress.

\section{Discussion}

In the pathogenesis of diabetic complications, there is an increasing evidence for the role of oxidative stress, which is manifested by enhanced lipid peroxidation, increased $F_{2}$ isoprostanes and superoxides, and increased protein and DNA damage (Davi et al 2005). HBO therapy is an exogenous factor that may cause an additional oxidative stress in the patients undergoing the treatment of diabetic foot ulcers. In the present study, oxidative stress was detected through the measurements of three markers - isoprostanes, malondialdehyde, and AOPPs - in diabetic patients before and after hyperbaric oxygen therapy. Isoprostane levels are known to vary depending on the availability of arachidonic acid, oxygen concentration, and generation of the ROS (Basu and Helmersson 2005). Apart from being

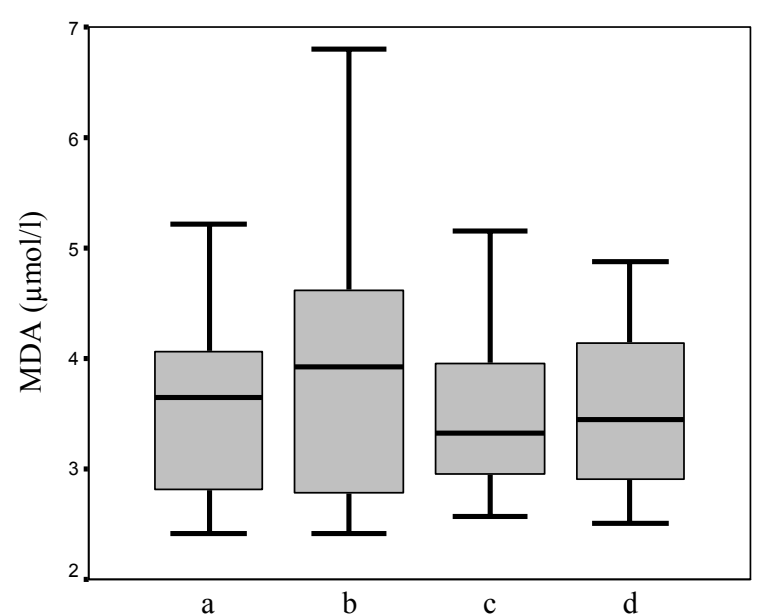

Fig. 3. Distribution of MDA levels in 20 patients. Boxes and lines represent the same characteristics as in Figures 1 and 2. (a) $1^{\text {st }}$ day before HBOT, (b) $1^{\text {st }}$ day after HBOT, (c) $15^{\text {th }}$ day before HBOT, (d) $15^{\text {th }}$ day after HBOT. b versus a: $\mathrm{p}<0.05$.

a sensitive marker of oxidative stress, 8 -isoprostanes are mediators of important biological effects. By contrast with MDA, 8-isoprostane acts through receptors able to elicit distinct signal transmission pathways (Comporti et al 2005). The ongoing increase of isoprostane concentration after fifteen sessions of HBO therapy suggest that isoprostane formation is independent of the adaptive response to oxidative stress. Since isoprostanes may affect the tissues as mediators of signal transmission, their association with some other clinical parameters needs to be investigated in detail.

It was previously shown that an initial HBO treatment of human subjects leads to the induction of adaptive response that protects cells against the induction of DNA damage by a second HBO treatment (Rothfuss $e t$ al 1998). It is also evident that ROS generated by HBO triggers the upregulation of antioxidant enzyme activities, thereby induces tolerance against ischemia in the tissues (Nie et al. 2006). In the present study, MDA was increased following the initial treatment of $\mathrm{HBO}$, while it remained unchanged on the day of the fifteenth HBO session. This finding is in accordance with the above mentioned reports as well as with our previous experiment that revealed significant increases in plasma MDA levels in rats following the first HBO treatment, but no change on the day of the 15th session (Korpinar and Cimsit, unpublished observations). Our current findings in diabetic patients indicate the upregulation of antioxidant enzymes by the initial HBOT. Although we did not measure the activities of antioxidant defense enzymes in this study, there is ample evidence to confirm 
this hypothesis (Kim et al. 2001, Harabin et al. 1990, Gregorevic et al. 2001).

AOPPs are elevated significantly in diabetes, and accumulation of AOPPs and AGEs in tissues play an important role in the diabetic long-term complications, including endothelial damage (Gillery 2001, De Cristofaro et al 2003). Plasma AOPP levels have been reported to correlate with concentrations of dityrosine and advanced glycation end-products as indices of oxidative protein damage, but not with thiobarbituric reactive substances as lipid peroxidation markers (Witko-Sarsat et al 1996, Gil-del Valle et al 2005). In agreement with above mentioned studies, we did not find any correlation between MDA and AOPP levels in diabetics. AOPP levels are tightly correlated with AGEs in both types of diabetes (Kalousová et al 2002). In our diabetic subjects, decreased AOPP level after successive HBO treatments may be related to the ROS-induced cellular signaling and protection. Furthermore, it is known that AOPP activates polymorphonuclear neutrophils and monocytes (WitkoSarsat et al. 2003), and activation of these cells aggravates the inflammatory reactions. Oxygen under pressure behaves as a drug causing both beneficial and toxic effects (Hink and Jansen 2001). HBO improves the oxygen delivery to the tissues, accelerates the rate of healing, and also has anti-infectious properties against various microorganisms (Mathieu et al. 2006). It has been proved by randomized, controlled clinical trials that HBOT is effective in diabetic wound healing (Abidia et al. 2003, Kalani et al. 2002). In our study, all the wounds were found in a better condition on the day of 15 th session compared to the initial state. A decreased formation of AOPPs, which is indicative of decreased protein damage, may be one of the consequences/contributors of the healing process. Furthermore, some exogenous factors that alter antioxidant status of the human body (e.g. smoking, use of statins) may significantly interact with the effects of HBOT on wound healing. However, our studied population was not large enough to determine the differences between subgroups.

In conclusion, this study supports the view that HBO triggers and upregulates the defense mechanisms against oxidative stress. Increased oxygenation of tissues due to HBOT may also activate other endogenous factors that prevent hazardous effects of the disease itself. In addition, it is now evident that drugs such as statins and ACE inhibitors have a strong intracellular antioxidant activity, and may therefore exert beneficial effects on diabetic vascular complications (Tsiara et al. 2003, Da Ros et al. 2004). The contribution of these drugs to the healing effect of $\mathrm{HBO}$ needs to be elucidated by further studies.

\section{Conflict of Interest}

There is no conflict of interest.

\section{Acknowledgements}

This study was supported by the Research Fund of Istanbul University, project no: 247/23082004. The authors wish to thank Associate Professor Halim Issever, Department of Public Health, Division of Biostatistics, Istanbul Faculty of Medicine, for his invaluable contribution to the statistical evaluations.

\section{References}

ABIDIA A, LADEN G, KUHAN G, JOHNSON BF, WILKINSON AR, RENWICK PM, MASSON EA, MCCOLLUM PT: The role of hyperbaric oxygen therapy in ischaemic diabetic lower extremity ulcers: a double-blind randomised-controlled trial. Eur J Vasc Endovasc Surg 25: 513-518, 2003.

ABOU-SEIF MA, YOUSSEF AA: Evaluation of some biochemical changes in diabetic patients. Clin Chim Acta 346: 161-170, 2004.

BASU S, HELMERSSON J: Factors regulating isoprostane formation in vivo. Antioxid Redox Signal 7: 221-235, 2005.

BUEGE JA, AUST JD: Microsomal lipid peroxidation. Methods Enzymol 52: 302-310, 1978.

COMPORTI M, AREZZINI B, SIGNORINI C, SGHERRI C, MONACO B, GARDI C: F2-isoprostanes stimulate collagen synthesis in activated hepatic stellate cells: a link with liver fibrosis? Lab Invest 85: 1381-1391, 2005.

DA ROS R, ASSALONI R, CERIELLO A: Antioxidant therapy in diabetic complications: what is new? Curr Vasc Pharmacol 2: 335-341, 2004.

DALTON TP, SHERTZER HG, PUGA A: Regulation of gene expression by reactive oxygen. Annu Rev Pharmacol Toxicol 39: 67-101, 1999.

DAVI G, FALCO A, PATRONO C: Lipid peroxidation in diabetes mellitus. Antioxid Redox Signal 7: 256-268, 2005. 
DE CRISTOFARO R, ROCCA B, VITACOLONNA E, FALCO A, MARCHESANI P, CIABATTONI G, LANDOLFI R, PATRONO C, DAVI G: Lipid and protein oxidation contribute to a prothrombotic state in patients with type 2 diabetes mellitus. J Thromb Haemost 1: 250-256, 2003.

DENNOG C, RADERMACHER P, BARNETT YA, SPEIT G: Antioxidant status in humans after exposure to hyperbaric oxygen. Mutat Res 428: 83-89, 1999.

EKEN A, AYDIN A, SAYAL A, USTUNDAG A, DUYDU, Y. DUNDAR K: The effects of hyperbaric oxygen treatment on oxidative stress and SCE frequencies in humans. Clin Biochem 38: 1133-1137, 2005.

FELDMEIER JJ: Hyperbaric oxygen: indications and results. The Hyperbaric Oxygen Therapy Committee Report. Undersea and Hyperbaric Medical Society. Maryland, USA, 2003.

GIL-DEL VALLE L, MILIAN LC, TOLEDO A, VILARO N, TAPANES R, OTERO MA: Altered redox status in patients with diabetes mellitus type I. Pharmacol Res 51: 375-380, 2005.

GILLERY P: Advanced glycation end products (AGEs), free radicals and diabetes (in French). J Soc Biol 195: 387-390, 2001.

GREGOREVIC P, LYNCH GS, WILLIAMS DA: Hyperbaric oxygen modulates antioxidant enzyme activity in rat skeletal muscles. Eur J Appl Physiol 86: 24-27, 2001.

HARABIN AL, BRAISTED JC, FLYNN ET: Response of antioxidant enzymes to intermittent and continuous hyperbaric oxygen. J Appl Physiol 69: 328-335, 1990.

HERRLICH P, BOHMER FD: Redox regulation of signal transduction in mammalian cells. Biochem Pharmacol 59: 35-41, 2000.

HINK J, JANSEN E: Are superoxide and/or hydrogen peroxide responsible for some of the beneficial effects of hyperbaric oxygen therapy? Med Hypotheses 57: 764-769, 2001.

JAMIESON DD: Lipid peroxidation in brain and lungs from mice exposed to hyperoxia. Biochem Pharmacol 41: 749$756,1991$.

KALANI M, JÖRNESKOG G; NADERI N, LIND F, BRISMAR K: Hyperbaric oxygen (HBO) therapy in treatment of diabetic foot ulcers. Long-term follow-up. J Diabetes Complications 16: 153-158, 2002.

KALOUSOVÁ M, ŠKRHA J, ZIMA T: Advanced glycation end-products and advanced oxidation protein products in patients with diabetes mellitus. Physiol Res 51: 597-604, 2002.

KIM CH, CHOI H, CHUN YS, KIM GT, PARK JW, KIM MS: Hyperbaric oxygenation pretreatment induces catalase and reduces infarct size in ischemic rat myocardium. Pflugers Arch 442: 519-525, 2001.

LIN HC, WAN FJ, WU CC, TUNG CS, WU TH: Hyperbaric oxygen protects against lipopolysaccharide-stimulated oxidative stress and mortality in rats. Eur J Pharmacol 508: 249-254, 2005.

MARTIN-GALLAN P, CARRASCOSA A, GUSSINYE M, DOMINGUEZ C: Biomarkers of diabetes-associated oxidative stress and antioxidant status in young diabetic patients with or without subclinical complications. Free Radic Biol Med 34: 1563-1574, 2003.

MATHIEU D, LINKE JC, WATTEL F: Non-healing wounds. In: Handbook on Hyperbaric Medicine. D. MATHIEU (ed), Springer, Netherlands, 2006, pp 401-427.

NIE H, XIONG L, LAO N, CHEN S, XU N, ZHU Z: Hyperbaric oxygen preconditioning induces tolerance against spinal cord ischemia by upregulation of antioxidant enzymes in rabbits. J Cereb Blood Flow Metab 26: 666$674,2006$.

OPARA EC: Oxidative stress, micronutrients, diabetes mellitus and its complications. J R Soc Health 122: 28-34, 2002.

OTER S, KORKMAZ A, TOPAL T, OZCAN O, SADIR S, OZLER M, OGUR R, BILGIC H: Correlation between hyperbaric oxygen exposure pressures and oxidative parameters in rat lung, brain, and erythrocytes. Clin Biochem 38: 706-711, 2005.

ROBERTS, LJ, MORROW JD: Measurement of $\mathrm{F}_{2}$-isoprostanes as an index of oxidative stress in vivo. Free Radic Biol Med 28: 505-513, 2000.

ROSETTE C, KARIN M: Ultraviolet light and osmotic stress: activation of the JNK cascade through multiple growth factor and cytokine receptors. Science 274: 1194-1197, 1996.

ROTHFUSS A, DENNOG C, SPEIT G: Adaptive protection against the induction of oxidative DNA damage after hyperbaric oxygen treatment. Carcinogenesis 19: 1913-1917, 1998. 
TSIARA S, ELISAF M, MIKHAILIDIS DP: Early vascular benefits of statin therapy. Curr Med Res Opin 19: 540-556, 2003.

WATTEL F: European Committee Consensus Conference on Hyperbaric Oxygen in the Treatment of Foot Lesions in Diabetic Patients. ECHM. Glaxo-Welcome, France, 1998.

WITKO-SARSAT V, FRIEDLANDER M, CAPEILLERE-BLANDIN C, NGUYEN-KHOA T, NGUYEN AT, ZINGRAFF J, JUNGERS P, DESCAMPS-LATSCHA B: Advanced oxidation protein products as a novel marker of oxidative stress in uremia. Kidney Int 49: 1304-1313, 1996.

WITKO-SARSAT V, GAUSSON V, NGUYEN AT, TOUAM M, DRUEKE T, SANTANGELO F, DESCAMPSLATSCHA B: AOPP-induced activation of human neutrophil and monocyte oxidative metabolism: a potential target for N-acetylcysteine treatment in dialysis patients. Kidney Int 64: 82-91, 2003.

YOGARATNAM JZ, LADEN G, MADDEN LA, SEYMOUR AM, GUVENDIK L, COWEN M, GREENMAN J, CALE A GRIFFIN S: Hyperbaric oxygen: a new drug in myocardial revascularization and protection? Cardiovasc Revasc Med 7: 146-154, 2006.

YU SY, CHIU JH, YANG SD, YU HY, HSIEH CC, CHEN PJ, LUI WY, WU CW: Preconditioned hyperbaric oxygenation protects the liver against ischemia-reperfusion injury in rats. $J$ Surg Res 128: 28-36, 2005. 